\title{
Hal 18-31
}

\section{STRATEGI DAN SISTEM PEMASARAN IKAN DI PANGKALAN PENDARATAN IKAN (PPI) BEBA KABUPATEN TAKALAR.}

\author{
Strategy And Marketing Fish Marketing System Of Fish Landing \\ (PPI) BEBA Takalar District. \\ Andi Teti', Danial Sultan'), Ihsan ${ }^{3)}$ \\ 1) Balai Pengelolaan Sumberdaya Pesisir dan Lau, Maros \\ ${ }^{2)}$ Program Studi Manajemen Pesisir dan Teknologi Kelautan, PPS UMI Makassar \\ 3) Program Studi Pemanfaatan Sumberdaya Perikanan FPIK UMI Makassar
}

Korespondensi : anditatati@gmail.ac.id

Diterima: tanggal 2 Januari 2019; Disetujui 31 April 2019

\begin{abstract}
ABSTRACK
Pendaratan Pendaratan Ikan (PPI) Beba is one of the most crowded Fish Port landing and fish market in Takalar Regency. The high trading volume and marketing of fish at PPI Beba has caused the need for an assessment of marketing efficiency to determine the effectiveness of fish marketing at the PPI Beba so that a Marketing Strategy can be arranged that is suitable with the conditions of fish marketing in the PPI Beba. This research was conducted from September to October 2018, using primary data and secondary data. The aim of this research are formulating fish marketing strategies at the PPI Beba North Galesong District Takalar Regency. Data analysis was carried out in several stages, namely by conducting namely by analyzing the margins and distribution of marketing, analyzing marketing effectiveness and then conducting the S.W.O.T analysis method (Strengthen, Weakness, Opportunities, and Threats) show that marketing margins were still more enjoyed by retailers and collectors than those received by fishermen. In addition, the analysis showed that the marketing efficiency of fish at PPI was still quite low. The results of analysis using the SWOT method show the marketing strategy of fisheries production at PPI It is necessary to pay attention to faktors that are significant to the condition of the PPI, activation of auction (TPI), develop marketing facilities and infrastructure, develop market access, modernize tools and fishing vessels, determine pricing, capital capabilities, knowledge of fishermen ranging from preproduction, processing to marketing to improve the welfare of fishermen.
\end{abstract}

Keyword: Strategy; Marketing; Fish Marketing System; Fish Landing; Takalar District

\begin{abstract}
ABSTRAK
Pangkalan Pendaratan Ikan (PPI) Beba merupakan salah satu Pangkalan Pendaratan Ikan dan pasar ikan yang paling ramai oleh aktifitas perdagangan dan pemasaran ikan di Kabupaten Takalar.Besarnya volume perdagangan dan pemasaran ikan di PPI Beba menyebabkan perlunya adanya penilaian efisiensi pemasaran untuk mengetahui tingkat efektifitas pemasaran ikan di PPI Beba sehingga dapat dirumuskan strategi pemasaran yang sesuai dengan kondisi pelaku pemasaran ikan di PPI Beba. Penelitian ini dilaksanakan pada bulan September sampai bulan Oktober 2018, menggunakan data primer dan data sekunder. Tujuan penelitian ini adalah untuk merumuskan strategi pemasaran ikan di pangkalan pendaratan ikan (PPI) Beba Kecamatan Galesong Utara, Kabupaten Takalar. Analisis data dilakukan dengan beberapa tahap yaitu dengan melakukan analisis terhadap margin pemasaran, analisis efektifitas pemasaran dan selanjutnya dilakukan metoda analisis S.W.O.T (Strengthen, Weakness, Opportunities, dan Threats) menunjukan strategi pemasaran hasil produksi perikanan di PPI Beba perlu memperhatikan faktor-faktor yang signifikan terhadap kondisi PPI, memfungsikan Tempat Pelelangan Ikan (TPI), pengembangan fasilitas dan infrastruktur pemasaran, pengembangan akses pasar, modernisasi alat dan kapal penangkap ikan, penentuan harga, kemampuan permodalan, pengetahuan nelayan mulai dari praproduksi, produksi pengolahan hingga pemasaran guna meningkatkan kesejahteraan nelayan.
\end{abstract}

Kata kunci: Strategi; sistem pemasaran ikan; pangkalan pendaratan ikan; Takalar. 
PENDAHULUAN

Di Sulawesi Selatan sampai dengan tahun 2012, terdapat 20 unit Pelabuhan Perikanan, salah satu diantaranya adalah Pangkalan Pendaratan Ikan (PPI) Beba yang berada di Kabupaten Takalar. Pangkalan Pendaratan Ikan (PPI) ini merupakan salah satu pusat dari kegiatan perikanan tangkap di Kabupaten Takalar. Jenis unit penangkapan ikan yang banyak di Kabupaten Takalar pada tahun 2011 adalah jaring insang, berjumlah 12.280 unit dengan hasil tangkapan sebesar 92\% dari total produksi ikan di Kabupaten Takalar (DKP Sulsel, 2012).

Untuk meningkatkan sektor ini diperlukan perancanaan simpul pemasaran dan produksi sehingga dengan sendirinya akan meningkatkan pendapatann nelayan melalui investasi yang dilakukan para investor. Salah satu Pelabuhan Perikanan yang ada di Provinsi Sulawesi Selatan adalah Pangkalan Pendaratan Ikan (PPI) Beba yang merupakan Pelabuhan Perikanan Kelas IV dan tipe D. Pelabuhan ini sangat ramai oleh aktifitas perdagangan dan pemasaran ikan tangkapan nelayan.
Pelabuhan

perikanan

merupakan pusat pemasaran hasil tangkapan, dimana peran dan sarananya sangat penting dalam perekonomian suatu pelabuhan yaitu mulai dari pendaratan sampai dengan pemasaran hasil tangkapan (Lubis 2011). Fungsi pelabuhan perikanan dalam pemasaran hasil tangkapan mencakup ketersediaan fasilitas, pelayanan dan ketersediaan sistem informasi. Ketiga indikator ini sangat penting dalam suatu pelabuhan perikanan.

Komoditi perikanan berfluktuasi menurut jumlah produksi dan harga. Fluktuasi produksi disebabkan hasil tangkapan yang tergantung pada musim, sedangkan fluktuasi harga diakibatkan oleh pergeseran permintaan dan penawaran ikan segar. Harga ikan segar hasil tangkapan akan menentukan perilaku pasar usaha tersebut. Apabila produksi harga rendah, maka pemasaran harus baik dan efisien (Yulianto et al., 2013).

Penelitian ini bertujuan untuk menentukan tingkat efisiensi pemasaran dan merumuskan strategi optimalisasi fungsi pelabuhan perikanan dalam pemasaran hasil tangkapan. 


\begin{abstract}
Penelitian ini berfokus pada komoditas ikan yang dominan dipasarkan di Pangkalan Pendaratan Ikan (PPI) Beba. Sifat khas suatu komoditas ikan ini adalah mudah mengalami pembusukan (perishable), sehingga menuntut para pedagang dan nelayan untuk melakukan tindakan
\end{abstract} penanganan yang cepat baik dalam proses produksi maupun selama pemasaran, guna menghindari turunnya kualitas dan harga ikan tersebut. Sistem pemasaran hasil tangkapan merupakan suatu kesatuan dari lembaga atau pelaku pemasaran yang berperan melakukan fungsi dalam pemasaran. Usaha perikanan tangkap di Pangkalan Pendaratan Ikan (PPI) Beba sampai saat ini masih didominasi oleh usaha perikanan tangkap skala kecil dengan tingkat produktivitas dan efisiensi usaha serta pendapatan yang masih rendah (DPT, 2004).

\section{METODOLOGI PENELITIAN}

Penelitian ini dilaksanakan selama 2 bulan dari mulai bulan September sampai Oktober 2018 di di PPI Beba Kabupaten Takalar. pengumpulan data data primer diperoleh melalui wawancara dan observasi langsung di pelabuhan serta di setiap lokasi ikan dipasarkan. Wawancara dengan responden dilakukan langsung di setiap lokasi dengan meruntut tiap pelaku dari PPI Beba hingga ke pedagang pengecer. Data sekunder yang dikumpulkan terkait dengan jumlah hasil tangkapan nelayan, volume ikan yang dipasarkan, harga ikan yang ada di PPI Beba, jumlah pengumpul dan jumlah distributor. Responden yang diwawancarai dan untuk pengisian kuisioner adalah nelayan dengan alat tangkap dominan purse sein dan pancing, tokoh masyarakat, pengumpul di darat, pengumpul laut, pedagang/bakul, serta distributor. Pengambilan responden dilakukan secara purposive sampling agar dapat mewakili tujuan penelitian. Pada penelitian ini, pengumpulan data data primer diperoleh melalui wawancara dan observasi langsung di pelabuhan serta di setiap lokasi ikan dipasarkan. Wawancara dengan responden dilakukan langsung di setiap lokasi dengan meruntut tiap pelaku dari PPI Beba hingga ke pedagang pengecer. Data sekunder yang dikumpulkan terkait dengan jumlah hasil tangkapan nelayan, volume ikan yang dipasarkan, harga ikan yang ada di PPI Beba, 
jumlah pengumpul dan jumlah distributor.

Pada penelitian ini, data sekunder akan didapatkan dari instansi sebagai berikut:

a) UPT PPI Beba mengenai data fasilitas pelabuhan dan asal ikan yang didaratkan di pelabuhan,

b) Dinas Kelautan dan Perikanan Provinsi Sulawesi Selatan mengenai informasi produksi dan nilai produksi ikan, pelaku usaha di Tempat Pelelangan Ikan, data statistik perikanan, serta lokasi tujuan distribusi ikan yang berasal dari PPI.Beba.

Populasi dalam penelitian ini adalah Pegawai, Ponggawa dan Pedagang yang ada di Pangkalan Pendaratan (PPI) Beba. Metode dalam pengambilan sampel adalah teknik nonprobability sampling dengan cara puposive sampling. Jumlah sampel ditentukan berdasarkan rumus Slovin yang dikutip oleh Zeithaml (2000, Hal 160):

$$
n=\frac{N}{1+n(E)^{2}}
$$

Dimana :

$\mathrm{n}=$ ukuran sampel

$\mathrm{N}=$ ukuran populasi
$\mathrm{E}=$ nilai kritis $/$ persentase kelonggaran $(0,1)$

Karakteristik responden terdiri dari konsumen atau pelanggan yang membeli berbagai ikan di Pangkalan Pendaratan Ikan (PPI) Paotere, penelitian ini secara garis besarnya meliputi karakteristik responden menurut jenis kelamin, umur, pendidikan terakhir, pekerjaan dan pendapatan responden. Data-data yang diperoleh kemudian diolah dengan menggunakan tabulasi silang, sehingga diperoleh gambaran secara menyeluruh dan terperinci jumlah total dari setiap item yang diteliti dan disusun menurut aliran baris dan kolom, sehingga akan mudah untuk diinterpretasikan secara kuantitatif.

\section{HASIL DAN PEMBAHASAN}

\section{Sistem Pemasaran di PPI Beba}

Sistem transaksi hasil tangkapan nelayan di PPI Beba pada umumnya dilakukan dengan mekanisme transaksi yang hamper sama dengan wilayah pesisir yang ada di Sulawesi Selatan. Dengan mekanisme transaksi yang berlaku secara umum bahwa nelayan yang memiliki kesepakatan/ikatan dengan ponggawa maka hasil tangkapannya dipasarkan kepada ponggawa tersebut, 
sedangkan bagi yang tidak memiliki hubungan bebas memasarkan hasil tangkapannya ke beberapa pedagang pengumpul maupun pedagang pendatang yang biasa ditemui di tengah laut dan di tempat pendaratan ikan di darat.

Proses transaksi dilakukan di atas kapal mulai dari sandarnya kapal nelayan kemudian ikan hasil tangkapan ditawar oleh ponggawa yang dijual kepada pedagang pengumpul atau paccato' dengan harga yang dijual lebih tinggi setelah pedagang pengumpul memiliki ikan dalam jumlah banyak kemudian dijual kepada pedagang pengecer untuk dijual secara eceran dan dijual kembali untuk kebutuhan rumah tangga dan konsumen.

Pola pemasaran dan distribusi ikan pada nelayan skala kecil tidak terlalu kompleks, sistim pemasaran ikan hanya berpindah tangan 2-3 kali sebelum sampai ke konsumen lokal. Begitu pula sistem pemasaran ikan di PPI Beba masih terbatas, sehingga masih perlu dikembangkan dan dimodifikasi (2017, Aprilia Syah Putri).

Sistem pemasaran yang dilakukan pengelola di PPI Beba
Takalar masih sangat jauh berbeda dengan cara pemasaran ikan dengan sistem lelang sesuai dengan petunjuk Menteri Pertanian No,64 tahun 1977. Hal ini disebabkan karena;

1) Kemampuan daya beli bakul (pedagang pengecer) sangat rendah, mengakibatkan ikan tidak habis dipasarkan. Dipihak lain, waktu pemasaran ikan di pasar-pasar Kota Takalar dan daerah target pemasaran seperti Kota Jeneponto Kota Gowa dan Kota Makassar,sangat terbatas yaitu 3 sampai dengan 4 jam setiap hari.

2) Kemampuan permodalan nelayan sangat rendah, sehingga sangat tergantung kepada punggawa yang ada di PPI Beba Takalar dan

3) Nelayan sudah terbiasa dengan meminjam uang dengan punggawa (pemilik modal) tanpa adanya persyaratan atau agunan.

Pemasaran ikan hasil tangkapannya nelayan yang didaratkan di PPI Beba Takalar dilakukan 1 (satu) kali sehari, yaitu pada pagi hari mulai jam 06.00-10.00 Wita Jika masih ada ikan yang tersisa (tidak habis terjual) 
pada sore hari, maka dipetieskan dan dijual pada keesokan harinya.

Kapal yang digunakan oleh nelayan dapat menampung sekitar 100 ekor ikan dan \pm 10 buah es balok. Di mana es balok tersebut digunakan agar ikan tidak membusuk ketika ditempatkan di dalam box dan ketika sampai di PPI ikan masih dalam keadaan segar. Ada juga kapal yang digunakan oleh nelayan dengan kapasitas yang cukup besar karena dapat menampung sekitar 500-600 ekor ikan dan \pm 100 buah es balok. Ikan biasanya pada hari itu juag tidak habis terjual biasanya ditempatkan di container untuk di jual keesokan harinya karena cold storage sudah tidak berfungsi lagi. Sistem pemasaran yang dilakukan nelayan di PPI Beba masih merupakan sistem pemasaran terbuka, dimana produksi hasil tangkapan ikan nelayan dijual cash kepada langsung kepada pedagang bakul dan pengusaha perikanan, dengan demikian para nelayan tidak menanggung resiko jika ikan tidak dapat dipasarkan atau rusak, sedangkan harga ikan yang dijual oleh pedagang pengecer di PPI Beba Takalar umumnya mengambil margin keuntungan sekitar $\quad 10 \%$ sampai dengan 20\% dari harga dasar pembelian dari ponggawa/nelayan.

\subsection{Margin dan Sebaran Pemasaran} Ikan

Berdasarkan data yang diperoleh dari wawancara dan data sekunder, volume jenis ikan dan harga per kilogram yang diperdagangkan di PPI Beba diketahui ikan yang memiliki nilai ekonomis yang cukup tinggi adalah Ikan Kakap Merah, Ikan Merah, Ikan Kerapu/Sunu, Katombo, Layang, Katamba (Lencam), Sibula, Cakalangm Jannati dan Tembang. Berdasarkan hasil analisis data yang diperoleh, rata-rata Ikan Kakap Merah dijual di PPI Beba sekitar Rp. 35.000,(Tiga puluh lima ribu rupiah) per Kilogram oleh pengecer. Ikan Merah dijual seharga Rp. 23.700,- (Dua puluh tiga ribu tujuh ratus rupiah). Ikan Kerapu/Sunu dijual seharga 22.200,Dua puluh dua ribu dua ratus rupiah. Ikan katombo dijual seharga Rp. 16.900,- (Enam belas ribu sembilan ratus rupiah). Ikan layang dijual seharga Rp. 16.500,- (enam belas ribu lima ratus rupiah).

Sebaran pemasaran PPI Beba mencakup pasar-pasar kecamatan lain di Kabupaten Takalar, Kabupaten Gowa, Kota Makassar dan Kabupaten 
Jeneponto. Sebaran pemasaran ikan paling banyak terdapat di pasar-pasar di wilayah Kabupaten Takalar, setelah itu di Kabupaten Gowa yang merupakan kabupaten terdekat dari Kabupaten Takalar. Sebaran pemasaran ikan juga ditemui di Pasar wilayah Kota Makassar dan Jeneponto yang kuantitasnya tidak jauh berbeda.

\subsection{Strategi Pemasaran Ikan di PPI} Beba

\section{Pengelolaan PPI Beba sebagai} pusat kegiatan perikanan di Kota Beba, diperlukan suatu pengarahan yang dijabarkan dalam bentuk strategis dan program pemasaran di PPI Beba dengan mempertimbangkan dimensi pembangunan berkelanjutan (ekologis, ekonomi sosial budaya dan kelembagaan).

Untuk mengarahkan strategi pemasaran di PPI Beba berdasarkan input data kondisi eksisting dan system pemasaran, maka dilakukan analisis dengan menggunakan analisis SWOT (Strengh, Weakness, Oppartunity, Treat). Analisis ini merupakan analisis alternatif yang digunakan untuk mengidentifikasi berbagai faktor secara sistematik dalam merumuskan strategi pengelolaan. Analisis SWOT merupakan pemilihan hubungan atau interaksi antar unsur-unsur internal yaitu kekuatan dalam kelemahan terhadap unsur-unsur eksternal, yaitu peluang dan ancaman.

Berdasarkan hasil identifikasi faktor internal dan eksternal didapatkan unsurr-unsur SWOT seperti berikut:

a. Faktor internal Hal pertama yang dilakukan dalam analisis SWOT adalah mengidentifikasi faktor internal meliputi kekuatan dan kelemahan yang ada pada sistem pemasaran di PPI Beba. Berikut ini adalah kekuatan dan kelemahan yang ada di Sistem pemasaran PPI Beba :

1. Kekuatan (strength)

- S1:Mempunyai fasilitas pokok, fungsional dan pendukung yang memadai.

- S2:PPI Beba terletak dilokasi yang strategis.

- S3:SDM sudah berpengalaman dibidang perikanan.

- S4:Pelayanan perijinan surat yang mudah.

- S5 :Akses ke PPI Beba secara geografis cukup baik.

2. Kelemahan (weakness)

- W1 : Besarnya selisih margin dari pengecer terhadap nelayan 
- W2 : Belum adanya Koperasi yang menaungi nelayan dan pelaku usaha

- W3 : Belum adanya mobile cold storage

- W4 :TPI belum beroperasi maksimal

b. Analisis faktor eksternal

1. Peluang (opportunity)

- O1 :Pangsa pasar perikanan yang potensial.

- O2 :Permintaan Ikan didaerah lain meningkat

- O3: Jumlah nelayan, armada penangkap lebih besar

\section{Ancaman (threat)}

- T1 :Fishing Ground semakin jauh.

- T2 : Faktor cuaca yang tidak menentu

- T3 : Penanganan hasil perikanan dari pendaratan pelelangan hingga distribusi.

- Skoring faktor dilakukan setelah faktor - faktor internal dan eksternal telah diketahui. Berikut adalah skoring nilai dan bobot untuk faktor internal dan eksternal PPI Beba. Untuk lebih jelasnya dapat dilihat pada Tabel 1 berikut:

Tabel 1. Hasil Internal Faktor Evaluation (IFE)

\begin{tabular}{|c|c|c|c|c|}
\hline No & Keterangan & Bobot & Rating & Skor \\
\hline $\mathbf{I}$ & \multicolumn{4}{|l|}{ Kekuatan } \\
\hline 1 & Mempunyai fasilitas yang memadai & 0.14 & 4 & 0.56 \\
\hline 2 & PPI Beba terletak di lokasi yang strategis & 0.12 & 3 & 0.36 \\
\hline 3 & $\begin{array}{l}\text { SDM sudah berpengalaman di bidang } \\
\text { perikanan }\end{array}$ & 0.08 & 2 & 0.16 \\
\hline 4 & Pelayanan perijinan surat yang mudah & 0.08 & 2 & 0.16 \\
\hline 5 & Akses ke PPI Beba cukup baik & 0.07 & 2 & 0.14 \\
\hline II & \multicolumn{4}{|l|}{ Kelemahan } \\
\hline 1 & $\begin{array}{l}\text { Besarnya selisih margin dari pengecer } \\
\text { terhadap nelayan }\end{array}$ & 0.14 & 4 & 0.56 \\
\hline 2 & $\begin{array}{l}\text { Belum adanya Koperasi yang menaungi } \\
\text { nelayan dan pelaku usaha }\end{array}$ & 0.13 & 3 & 0.39 \\
\hline 3 & Belum adanya mobile cold storage & 0.09 & 2 & 0.18 \\
\hline \multirow[t]{2}{*}{4} & TPI belum beroperasi maksimal & 0.15 & 4 & 0.6 \\
\hline & Jumlah & 1 & & 3.11 \\
\hline
\end{tabular}


PPI Beba Takalar saat ini memiliki fasilitas yang cukup memadai antara lain seperti yang telah diuraikan sebelumnya, fasilitas yang terdapat di PPI Beba Takalar antara lain; Dermaga (Panjang $=68,5 \mathrm{~m}$ ); Jalan kawasan (Panjang $=100 \mathrm{~m}$, Lebar $=4,3 \mathrm{~m}$ ); Kantor Administrasi Pelabuhan; Tempat Pelelangan Ikan ; Pabrik Es ; Cold Storage; Air Bersih dan Jaringan Listrik.PPI Beba Takalar juga berada pada posisi yang strategis yang tidak jauh dari Jalan Propinsi penghubung antara Kota Makassar, Takalar, Jeneponto, Bantaeng dan Bulukumba.Secara kualitas, SDM yang menangani PPI Beba Takalar sudah cukup bagus dan memiliki kualifikasi standar yang dibutuhkan, akan tetapi jumlahnya masih sangat terbatas sehingga skor nilai yang tidak mencapai angka yang maksimal. Hal ini berimbas kepada pelayanan perijinan yang masih belum maksimal dikarenakan terbatasnya jumlah SDM. Akses menuju PPI Beba juga belum maksimal dikarenakan belum teraturnya penjual kaki lima yang menjual ikan olahan sebagai makanan/kuliner. Untuk itu skor nilai yang diberikan untuk akses ini masih belum mencapai nilai tertinggi.Jika dilihat dari Kelemahan yang ada, dari hasil wawancara dan olah data dapat diketahui besarnya selisih margin dari pengecer terhadap nelayan. Hal ini memperlihatkan masih panjangnya rantai distribusi penjualan dari nelayan sampai ke konsumen sehingga harus melewati beberapa tahapan perantara. Belum adanya koperasi yang menaungi nelayan menyebabkan nelayan tidak memiliki kekuatan pengawasan untuk mengetahui harga jual ikan. Selain itu belum adanya mobile cold storage menyebabkan mobilitas sebaran ikan juga terbatas dan perlakuan ikan hasil tangkapan kurang begitu baik sehingga ikan mudah rusak. TPI yang berada di PPI Beba Takalar yang sudah ada belum difungsikan sebagaimana mestinya sehingga penjual/pengecer ikan membuka lapaknya secara seenaknya dan tidak teratur sehingga memberikan kesan kumuh dan tidak baik dari sisi pemasaran. Hal ini menyebabkan nilai skor kelemahan tertinggi disematkan kepada TPI yang tidak berfungsi secara maksimal dan tingginya selisih margin penjualan ikan dapat dilihat pada Tabel 2 berikut:

Tabel 2. Hasil External Faktor Evaluation(IFE) 


\begin{tabular}{|c|c|c|c|c|}
\hline No & Keterangan & Bobot & Rating & Skor \\
\hline III & \multicolumn{3}{|l|}{ Peluang } & \\
\hline 1 & $\begin{array}{l}\text { Pangsa pasar } \\
\text { perikanan } \\
\text { yang } \\
\text { potensial }\end{array}$ & 0.24 & 4 & 0.96 \\
\hline 2 & $\begin{array}{l}\text { Harga ikan } \\
\text { stabil } \\
\text { cenderung } \\
\text { naik }\end{array}$ & 0.21 & 3 & 0.63 \\
\hline 3 & $\begin{array}{l}\text { Meningkatny } \\
\text { a jumlah } \\
\text { permintaan } \\
\text { ikan di tandai } \\
\text { dengan } \\
\text { meningkatny } \\
\text { a jumlah } \\
\text { nelayan, } \\
\text { armada, dan } \\
\text { ikan }\end{array}$ & 0.19 & 3 & 0.57 \\
\hline IV & \multicolumn{4}{|l|}{ Ancaman } \\
\hline 1 & $\begin{array}{l}\text { Fishing } \\
\text { Ground } \\
\text { semakin jauh }\end{array}$ & 0.16 & 2 & 0.32 \\
\hline 2 & $\begin{array}{l}\text { Faktor cuaca } \\
\text { yang tidak } \\
\text { menentu }\end{array}$ & 0.13 & 2 & 0.26 \\
\hline 3 & $\begin{array}{l}\text { Kurangnya } \\
\text { kemampuan } \\
\text { nelayan } \\
\text { dalam } \\
\text { penanganan } \\
\text { hasil } \\
\text { perikanan } \\
\text { dari } \\
\text { pendaratan } \\
\text { pelelangan } \\
\text { hingga } \\
\text { distribusi }\end{array}$ & 0.07 & 1 & 0.07 \\
\hline & Jumlah & 1 & & 2.81 \\
\hline
\end{tabular}

Hasil penilaian faktor eksternal

diketahui PPI Beba Takalar merupakan pangsa perikanan yang potensial mengingat letaknya yang tidak jauh dari kota Makassar yang memiliki jumlah penduduk yang besar dan akses menuju PPI Beba Takalar dapat ditempuh hanya dengan waktu
15-25 menit dari pusat Kota Makassar. Harga ikan yang cenderung stabil dan naik memberikan peluang yang besar bagi para pelaku usaha perikanan, akan tetapi yang harus diatur adalah tidak terjadi kesenjangan antar pelaku usaha terutama untuk nelayan yang berada di bagian hulu. Meningkatnya permintaan mendorong peningkatan jumlah armada perikanan, apalagi tingkat konsumsi ikan Kota Makassar cenderung memiliki angka yang tinggi menurut BPS. Ditengah peluang yang sangat menjanjikan juga terdapat beberapa ancaman antara lain wilayah fishing ground semakin jauh untuk mencari sumber ikan, cuaca yang sukar diprediksi akibat efek global seperti menipisnya ozon dan efek rumah kaca serta masih belum terampilnya nelayan menangani hasil tangkapan dari penangkapan sampai pendaratan dan distribusi menyisakan tantangan yang harus dihadapi PPI Beba Takalar. Dari hasil pembobotan terhadap faktor - faktor yang berpengaruh diperoleh hasil bahwa faktor - faktor internal (kekuatan dan kelemahan) lebih besar pengaruhnya dibandingkan dengan faktor eksternal (peluang dan ancaman), terhadap pengelolaan dan pemanfaatan PPI 
Beba, dengan rasio sebesar 3,11:2,81.

\section{Analisis Matriks SWOT}

\section{Penggunaan matriks SWOT}

setelah diidentifikasi faktor-faktor apa

saja yang mempengaruhi PPI Beba

baik faktor internal maupun eksternal

yang terdiri dari kekuatan, kelemahan, peluang dan ancaman yang mungkin dapat menghambat kemajuan, maka dapat disusun sebuah matriks kemungkinan. Matriks ini dapat menghasilkan 4 set kemungkinan alternatif strategis dapat dilihat pada Tabel 3 berikut:

Tabel 3. Matriks SWOT hasil analisa Strategi Pemasaran Pangkalan Pendaratan Ikan Beba (kekuatan, kelemahan dengan peluang).

\begin{tabular}{|c|c|c|}
\hline & $\begin{array}{l}\text { Kekuatan (strength) } \\
\text { 1. Mempunyai fasilitas memadai. } \\
\text { 2.PPI Beba terletak dilokasi yang } \\
\text { strategis. } \\
\text { 3. SDM sudah berpengalaman } \\
\text { dibidang perikanan. } \\
\text { 4. Pelayanan perijinan surat yang } \\
\text { mudah. } \\
\text { 5. Akses ke PPI Beba cukup baik. }\end{array}$ & $\begin{array}{l}\text { Kelemahan (weakness) } \\
\text { 1. Besarnya selisih margin dari } \\
\text { pengecer terhadap nelayan } \\
\text { 2. Belum adanya Koperasi yang } \\
\text { menaungi nelayan dan pelaku usaha } \\
\text { 3. Kebersihan lingkungan kurang } \\
\text { terjaga } \\
\text { 4. TPI tidak beroperasi }\end{array}$ \\
\hline Peluang (opportunity) & Strategi S-O & Strategi W - O \\
\hline $\begin{array}{l}\text { 1.Pangsa pasar } \\
\text { perikanan yang } \\
\text { potensial } \\
\text { 2. Harga ikan stabil } \\
\text { cenderung naik. } \\
\text { 3. Meningkatnya jumlah } \\
\text { permintaan ikan } \\
\text { ditandai dengan } \\
\text { meningkatnya jumlah } \\
\text { nelayan, armada, ikan }\end{array}$ & $\begin{array}{l}\text { 1. Pemanfaatan fasilitas secara } \\
\text { maksimal agar dapat } \\
\text { menampung,mengolah dan } \\
\text { mendistribusikan lebih banyak } \\
\text { hasil tangkapan } \\
\text { 2. Pengembangan system informasi } \\
\text { terpadu meliputi cuaca,harga } \\
\text { ikan dan peluang pasar ikan } \\
\text { 3. Pemeliharaan dan } \\
\text { pengembangan fasilitas Pokok, } \\
\text { Fungsional dan Penunjang } \\
\text { Pelabuhan Perikanan }\end{array}$ & $\begin{array}{l}\text { 1. Mengintervensi rantai pemasaran } \\
\text { ikan agar tdk terlalu panjang } \\
\text { 2. Pengembangan transportasi mobil } \\
\text { cold storage } \\
\text { 3. Membuat koperasi nelayan agar } \\
\text { tidak terjerat rentenir sehingga biaya } \\
\text { produksi tidak tergantung dari } \\
\text { ponggawa/pengumpul yang dapat } \\
\text { memainkan harga dan } \\
\text { memperpanjang rantai pemasaran }\end{array}$ \\
\hline Ancaman (Thread) & Strategi $\mathbf{S}-\mathbf{T}$ & Strategi $O$ \\
\hline $\begin{array}{l}\text { 1. Fishing Ground } \\
\text { semakin jauh. } \\
\text { 2. faktor cuaca yang } \\
\text { tidak menentu } \\
\text { 3. Kurangnya } \\
\text { kemampuan nelayan } \\
\text { dalam penanganan } \\
\text { hasil perikanan dari } \\
\text { pendaratan pelelangan } \\
\text { hingga distribusi. }\end{array}$ & $\begin{array}{l}\text { 1) Memberikan penyuluhan dan } \\
\text { pembinaan serta menfasilitasi } \\
\text { nelayan kecil untuk } \\
\text { meningkatkan skala usahanya } \\
\text { 2) Pengembangan Sumber Daya } \\
\text { Manusia dari nelayan terkait } \\
\text { peningkatan hasil mutu } \\
\text { perikanan dan manajemen } \\
\text { pemasaran } \\
\text { 3) Penerapan system lelang di PPI } \\
\text { beba }\end{array}$ & $\begin{array}{l}\text { 1. Memfasilitasi nelayan atau } \\
\text { pengusaha lokal untuk melakukan } \\
\text { kerjasama dengan pengusaha } \\
\text { nasional terkait pemasan ikan dan } \\
\text { ekspor } \\
\text { 2. Pengembangan fungsi PPI untuk } \\
\text { menjaga stabilitas harga ikan }\end{array}$ \\
\hline
\end{tabular}




\section{Grand Strategy}

Posisi Strategi digunakan untuk menentukan pilihan pada ke empat strategi yang telah didapatkan oleh analisa matrik SWOT, yaitu cara menempatkan total skor pada faktor internal dan eksternal matrik. Dari perhitungkan skorsing faktor total nilai skor utuk faktor internal didapatkan 3,11 , sedangkan untuk faktoreksternal didapatkan 2,81, selanjutnya ditempatkan dalam matrik. Untuk lebih jelasnya dapat dilihat dalam matrik strategi dibawah ini:

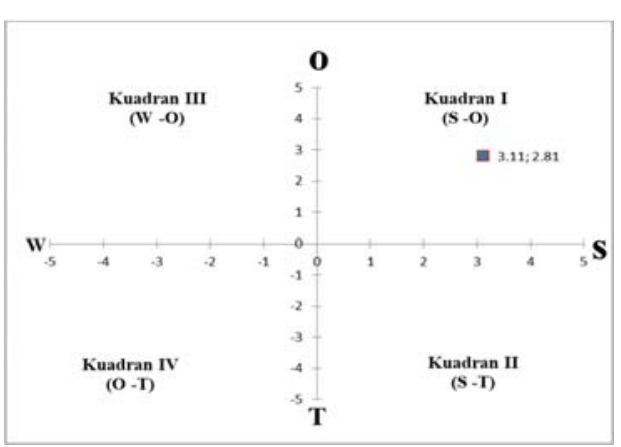

Gambar 1. Matriks Posisi Strategi SWOT

Berdasarkan matriks di atas, diatas dapat diketahui bahwa strategi yang dipilih adalah strategi pada kuadran I yaitu strategi S-O (StrengthOpportunity), maka dapat digunakan untuk meningkatkan pemasaran di Pangkalan Pendaratan Ikan Beba sehingga dapat lebih mengurangi margin dari pengecer ke nelayan dan memperpendek rantai pemasaran fasilitas yang ada di PPI Beba. Adapun Strategi yang terdapat pada kuadran I S-O (Kekuatan dan Peluang) yaitu :

1. Pemanfaatan fasilitas secara maksimal agar dapat menampung, mengolah dan mendistribusikan lebih banyak hasil tangkapan

2. Pengembangan system informasi terpadu meliputi cuaca,harga ikan dan peluang pasar ikan

3. Pemeliharaan dan pengembangan fasilitas Pokok, Fungsional dan Penunjang Pelabuhan Perikanan

Strategi yang terdapat pada kuadran II S-T (Kekuatan dan Ancaman) yaitu:

1. Memberikan penyuluhan dan pembinaan serta menfasilitasi nelayan kecil untuk meningkatkan skala usahanya

2. Pengembangan Sumber Daya Manusia dari nelayan terkait peningkatan hasil mutu perikanan dan manajemen pemasaran

3. Penerapan system lelang di PPI beba

Strategi yang terdapat pada kuadran IV W-O (Kekuatan dan Ancaman) yaitu:

1. Mengintervensi rantai pemasaran ikan agar tidak terlalu panjang

2. Pengembangan transportasi mobil cold storage 
3. Membuat koperasi nelayan agar tidak terjerat rentenir sehingga biaya produksi tidak tergantung dari ponggawa/pengumpul yang dapat memainkan harga dan memperpanjang rantai pemasaran.

Strategi yang terdapat pada kuadran IV O-T (Peluang dan Ancaman) yaitu:

1. Memfasilitasi nelayan atau pengusaha lokal untuk melakukan kerjasama dengan pengusaha nasional terkait pemasan ikan dan ekspor

2. Pengembangan fungsi PPI untuk menjaga stabilitas harga ikan

\section{KESIMPULAN}

Penelitian tentang Analisis Strategi Dan Sistem Pemasaran Ikan Di Pangkalan Pendaratan Ikan Beba Kabupaten Takalar menyimpulkan bahwa strategi pemasaran hasil produksi perikanan di PPI Beba perlu memperhatikan faktor-faktor yang signifikan terhadap kondisi PPI, memfungsikan TPI, pengembangan fasilitas dan infrastruktur pemasaran, pengembangan akses pasar, modernisasi alat dan kapal penangkap ikan, penentuan harga, kemampuan permodalan, pengetahuan nelayan mulai dari praproduksi, produksi pengolahan hingga pemasaran guna meningkatkan kesejahteraan nelayan.

\section{UCAPAN TERIMA KASIH}

Tulisan ini merupakan bagian dari penelitian dasar unggulan perguruan tinggi dan penulis mengucapkan terima kasih kepada Balai Pengelolaan Pesisir dan Laut yang telah memberi izin untuk melanjutkan studi.

\section{DAFTAR PUSTAKA}

Aprilia SyahPutri. 2017. Strategi Optimalisasi Fungsi Pelabuhan Perikanan Dalam Pemasaran Hasil Tangkapan Di PPP Lempasing. Jurnal Albacore Vol I. No.2 Hal 171-183

Assauri, Sofyan. 2008. Manajemen Pemasaran, edisi kedua, cetakan kesembilan, Jakarta: Raja Grafindo persada

Danial, Darmawan, John Haluan, Mustaruddin. 2011. Model Pengembangan Industri Perikanan Berbasis Pelabuhan Perikanan Di Kota Makassar Sulawesi Selatan. Makassar. Fakultas Perikanan dan Ilmu Kelautan Universitas Hasanuddin.

Danial, Hamsiah, Syahrul. Sukmawati.S, Muh.Yusuf 2018. A Model of Fish Marketing at Paotere Fishing Ports For Increaseing Fiherman's Income. Makassar. .International Journal of Development Research Vol.8, Issue 04, pp.2001320018. 
David, Fred R. 2009. Manajemen Strategis. Dinas Kelautan, dan Perikanan .Laporan Dinas Kelautan dan Perikanan. Sulawesi Selatan.2012

Harlisa.dkk. Hubungan Kondisi Sumberdaya Ikan Dengan Pelarangan Penggunaan Alat Tangkap Pukat Tarik Di Kabupaten Takalar Sulawesi Selatan.Jurnal Ilmu dan Teknologi Kelautan Tropis Vol.10 No.1Hal.59-68

Huda, Miftachul.2017.Tingkat efisien pemasaran ikan laut segar di Pelabuhan Perikanan Nusantara Brodong.Tesis tidak diterbitkan. Bogor .Sekolah Pascasarjana Institut Pertanian Bogor

LubisE.2011.Kajian peran strategis pelabuhan perikanan terhadap pengembangan perikanan laut.
Jurnal Sumberdaya Perairan $.2(5): 1-11$.

Puspitasari N, Ririn I, Adi S.2013. Strategi pengembangan Pelabuhan Perikanan Nusantara Karangantu Kota SerangP rovinsi Banten. Jurnal Ilmu Pertanian dan Perikanan. 1(2):159-169.

RangkutiF.2011.Analisis SWOT. Teknik Membedah Kasus Bisnis. Jakarta (ID): PT. Gramedia Pustaka Utama Kompas Gramedia Building.246 hlm.

RosmawatiH. 2011.Analisis efisiensi pemasaran pisang produksi petani di Kecamatan Lengkiti

Tomek, William G., \& Kenneth L. Robinson. 1990. Agricultural Product Prices. Cornell University Press. New York. 